\title{
Nizip Yağlık, Saurani ve Uslu Zeytin Çeşitlerinin Döllenme Biyolojilerinin Araştırılması
}

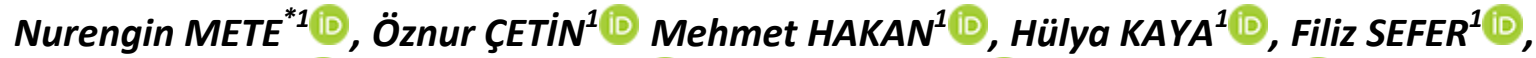 Nurcan ULUÇAY $Y^{1}$, Uğur GÜLOĞLU ${ }^{1}$, Hükümran GÜL ${ }^{1}$ (D) oktay SEZGiN ${ }^{1}$}

\section{${ }^{1}$ Zeytincilik Araştırma Enstitüsü, Bornova / Izmir}

Öz: Bu çalışma ile Türkiye zeytin ağaç varlığında önemli bir yer tutan Saurani, Nizip yağlık ve Uslu çeşitlerinin döllenme biyolojileri araştııı ış̧tır. Bu amaçla 3 yıl süre ile serbest tozlanma, karşııklı tozlama ve kendileme uygulamaları yapılarak çeşitlerin kendine verimlilik durumu ve uygun tozlayıcıları incelenmiştir. Çalışma neticesinde çeşitlerin kendine verimliliği ve tozlayıcıların etkinlik derecelerinin yıllar arasında değişebileceği görülmüştür. Bununla birlikte, yabancı tozlanmanın kendileme uygulamasına göre birçok durumda meyve tutumunu arttırdığı saptanmıştır. Bu nedenle kendine verimli olduğu düşünülen çeşitlerde dahi yabancı tozlanmanın gerekliliği ortaya konmuştur. Çalışmada, Nizip yağlık çeşidi kısmen kendine verimli olarak değerlendirilmiştir. Memecik ve Kilis yağlık çeşitlerinin Nizip yağlık çeşidi için uygun tozlayıcılar olabileceği düşünülmektedir. Saurani zeytin çeşidi verimlilik indeks değerlerine göre kendine verimli olarak bulunmuştur. Ancak meyve tutumunu arttırmak için Halhalı çelebi, Gemlik, Memecik ve Nizip yağlık çeşitlerinin uygun tozlayıcılar olarak kullanılabileceği düşünülmektedir. Uslu çeşidi de verimlilik indeks değerlerine göre kendine verimli olarak saptanmıştır. Bununla birlikte Gemlik, Memecik ve Erkence çeşitlerinin meyve tutumunu arttırmada etkili olduğu görülmüştür.

Anahtar Kelimeler: zeytin, meyve tutumu, tozlayıcı, döllenme biyolojisi

\section{Investigation of the Fertilization Biology of Nizip Yaglik, Saurani and Uslu Olives Cultivars}

Abstract: In this study, fertilization biology of Nizip Yaglik, Uslu and Saurani olive cultivars, which are important in the population of Turkey's olive trees, has been researched. The aim of the study have been determinated the self-compatibility status of the cultivars and suitable pollinators by open pollination, cross pollination and self-pollination applications in 3 years. As a result of the study, it has been observed that the cultivars self-compatibility and suitable pollinators may vary from year to year. However, it has been found that cross pollination increases the fertility to self-pollination in many cases. For this reason, the necessity of cross pollination has been revealed in the cultivars even which are thought to be self-pollinated. In the study, the Nizip Yaglik cultivar was partially evaluated as self-compatible. Memecik and Kilis yaglik are thought to be suitable pollinators for Nizip Yaglik. The Saurani olive cultivar has been found to be selfcompatible according to the fertility index value. Nevertheless, It is thought that Halhali çelebi, Gemlik, Memecik and Nizip Yaglik cultivars can be used as suitable pollenizers to increase the fruit set in Saurani. Uslu cultivar has been found to be self-compatibles according to the fertility index value. On the other hand Gemlik, Memecik and Erkence cultivars have been found to be effective in increasing of fruit set.

Keywords: olive, fruit-set, pollinator, fertilization biology

\section{Giriş}

Zeytin ilk olarak Doğu Akdeniz'de kültüre alınmış ve bu bölgeden zamanla tüm Akdeniz havzasına yayılmış durumdadır. Paleobotanik kanıtlar zeytinyağının bronz çağından beri üretildiğini göstermiştir (Unver ve ark., 2017). Tarih öncesinden günümüze genellikle sofralık zeytin ve zeytinyağı şeklinde değerlendirilen zeytin ürünleri Akdeniz Havzasının en önemli tarımsal ürünlerinden birisi olarak görülmektedir. Türkiye'deki zeytin alanları Ege, Akdeniz, Marmara ve Güneydoğu Anadolu bölgelerinde yaygınlaşmış durumdadır. Ülkemizde yetiştirilmekte olan zeytin çeşitlerinin tamamına yakını doğadan seleksiyon yöntemiyle elde edilmiştir (Mete ve Çetin 2017a). Türkiye zeytin biyoçeşitliliği bakımından da oldukça zengin konumda olup farklı bölgelerimizde ıslah edilmiş ve bölgesel olarak yaygınlaşmış birçok çeşidimiz bulunmaktadır. Ancak Türkiye'de zeytin yetiştiriciliği ülke genelinde monokültürel olarak yapılmakta ve tozlayıcı çeşit kullanımı konusunda bazı eksiklikler görülmektedir. Zeytin çeşitlerinin kendine verimliliği konusunda yapılan birçok çalışmada incelenen çeşitlerin büyük çoğunluğunun kendine verimsiz ya da kısmen kendine verimli olduğu belirlenmiştir. Uygun tozlayıcı kullanımının zeytinde verimliliğin artırılmasında yararlı olacağı da ifade edilmiştir (Mete ve ark., 2015). Hatta bazı araştırıcılar kendine verimli olan çeşitlerde bile uygun tozlayıcı çeşit kullanımının verime olumlu etki yaptığını belirtmişlerdir (Lombardo ve ark., 2006, Mete ve ark., 2012). Bu konuya ilişkin Ferrara ve ark., (2002), tek çeşitle kurulan zeytin bahçelerindeki verim düşüklüğünün, en önemli nedeninin kendine uyuşmazlık olduğunu ifade etmişlerdir. Bununla birlikte zeytinde kendine uyuşmazlık mekanizmasının genetik faktörler ve çevresel koşulların etkisi altında olduğu bildirilmiştir (Lavee ve ark., 2002). Birçok çalışmada tozlayıcı çeşit kullanımının meyve tutumunu artırdığı görülmüş ve bahçe tesisinde tozlayıcı çeşit bulundurmanın gerekliliği vurgulanmıştır (Lombardo

Sorumlu Yazar: nurenginmete@gmail.com Bu çalışma TAGEM/BBAD/10/A08/P06/18 nolu proje kapsamında desteklenmiştir.

Geliş Tarihi: 28 Mayıs2018

Kabul Tarihi: 18 Nisan 2019 
ve ark., 2006; Vulletin Selak ve ark., 2006; Farinelli ve ark., 2008; Mete ve ark., 2016). Türkiye'de zeytin çeşitlerinin döllenme biyolojilerine ilişkin yapılan araştırmalarda şu ana kadar 16 farklı çeşit çalışılmıştır. Bu çalışmalarda Edincik su, Samanlı ve Hayat çeşitleri kendine verimli; Ayvalık, Çakır, Erkence, Gemlik, Memecik, Memeli, Yamalak sarısı ve Domat çeşitleri kısmen kendine verimli; İzmir Sofralık, Eşek zeytini (Ödemiş) ve Kilis Yağlık çeşitleri kendine verimsiz olarak saptanmışlardır (Çavuşoğlu, 1970; Sütçü, 1980; Kaya ve Tekintaş 2006; Mete ve Mısırlı 2009; Mete ve ark., 2012, Mete ve ark., 2016; Mete ve Çetin 2017b).

Bu çalışma ile ülkemizin önemli zeytin çeşitlerinden olan Uslu, Saurani ve Nizip Yağlık çeşitlerinin kendiyle uyuşma durumu ve uygun tozlayıcılarının saptanması amaçlanmıştır.

\section{MATERYAL VE YÖNTEM}

Çalışmada Zeytin Arazi Gen Bankası'nda (Kemalpaşa / İzmir, 38²7'49.94"K, $\left.27^{\circ} 22^{\prime} 33.64^{\prime \prime D}\right)$ bulunan yaklaşık 40 yaşındaki Uslu, Nizip Yağıık ve Saurani çeşitleri materyal olarak kullanılmıştır. Arazi Gen Bankası'nda bulunan Ayvalık, Çekişte, Edincik, Eğri burun (Nizip), Erkence, Gemlik, Halhalı Çizelge 1 . Kendine uyuşma durumu ve tozlayıcıların sınıflandııılması çelebi, Kilis yağlık, Memecik, Sarı ulak, Tavşan yüreği, Yağlık çelebi, Yuvarlak halhalı çeşitleri tozlayıcı olarak kullanılmışlardır. Çalışma 2012-2014 yıllarında yürütülmüştür.

Meyve tutum oranını belirlemek amacıyla serbest tozlanma, kendileme ve karşılıklı tozlama uygulamaları gerçekleştirilmiştir. Karşılıklı tozlama uygulamaları iki kez tekrarlanmıştır.

Meyve sayımları tam çiçeklenmeden yaklaşık 5 ay sonra gerçekleştirilmiştir. Meyve tutum miktarı somak başına düşen meyve miktarı şeklinde hesaplanmıştır. Çeşitlerin kendine verimlilik durumu ve tozlayıcıların etkinliği verimlilik indeksi $\quad(R)$ formülüne göre hesaplanmıştır. Elde edilen bulgular Çizelge 1 dikkate alınarak değerlendirilmiştir (Moutier, 2002). Çalışma, tesadüf parselleri deneme desenine göre kurulmuştur. Elde edilen verilerin istatistiksel analizi Student's $t$ gruplandırma testi uygulanarak yapılmıştır.

$R=\frac{\text { Kendileme ya da karşılıklı tozlamadaki meyve tutum oranı }}{\text { Serbest tozlamadaki meyve tutum oranı }}$

Kendine Verimlilik ve Karşılıklı Tozlanma

R değeri $-0.00 \geq$ Kendine verimsiz $<0.15 \geq$ Kısmen kendine verimli $<0.30 \geq$ Kendine verimli $\leq 1.00$

R değeri $-0.00 \geq$ Kötü tozlayıcı $<0.33 \geq$ Kabul edilebilir tozlayıcı $<0.66 \geq$ İyi tozlayıcı $\leq 1.00$

\section{BULGULAR VE TARTIŞMA}

Uslu: Ülkemizin önemli siyah sofralık çeşitlerinden birisi olan Uslu çeşidinde, üç farklı yılda gerçekleştirilen uygulamalara ilişkin bulgular Çizelge 2'de izlenmektedir. Denemenin birinci yılında (2012) en yüksek meyve tutum oranı 0.368 ile serbest tozlanmada, en düşük meyve tutum oranı ise 0.133 ile kendileme uygulamasında belirlenmiştir. Tozlayıcı çeşitlerden Memecik 0.335 oranı ile aynı yıl iyi bir tozlayıcı olmuştur. Diğer çeşitlerin meyve tutum miktarları ise sırasıyla 0.233 (Edincik), 0.223 (Ayvalık), 0.219 (Tavşan yüreği), 0.213 (Erkence) ve 0.178 (Çekişte) şeklinde gerçekleşmiştir. İkinci yıl (2013) uygulamalarda Memecik
(0.518), Gemlik (0.510), Erkence (0.467) ve Tavşan yüreği (0.412) çeşitleri serbest tozlanmaya (0.372) göre çok daha yüksek meyve tutum oranına sahip olmuşlardır. Bu duruma çiçeklenme boyunca aralıklı olarak süren yağışların etkili olduğu düşünülmektedir. İkinci yıl Ayvalık ve Edincik su çeşitlerinde ise sırasıyla 0.281 ve 0.240 'lık meyve tutum oranı belirlenmiştir. Çalışmanın üçüncü yılı (2013) en yüksek meyve tutum miktarı 0.427 ile kendilemede, en düşük meyve tutum miktarı ise 0.337 ile Tavşan yüreği çeşidinde saptanmıştır. Diğer uygulamalar bu iki değer arasında yer almıştır. Ancak istatistiksel analiz sonucunda tüm uygulamalar arasında bir farklılık ortaya çıkmamıştır.

Çizelge 2. Uslu çeşidine ait meyve tutum ve verimlilik indeks $(R)$ değerleri

\begin{tabular}{|c|c|c|c|c|c|c|c|c|}
\hline \multicolumn{3}{|c|}{ 1. YII } & \multicolumn{3}{|c|}{ 2. YII } & \multicolumn{3}{|c|}{ 3. Yll } \\
\hline Uygulama & SBDM* & $\mathbf{R}$ & Uygulama & SBDM* & $\mathbf{R}$ & Uygulama & SBDM* & $\mathbf{R}$ \\
\hline Serbest tozlanma & $0.368 a$ & 1.00 & Serbest tozlanma & $0.372 a b c$ & 1.00 & Serbest tozlanma & 0.404 & 1.00 \\
\hline Kendileme & $0.133 \mathrm{c}$ & 0.36 & Kendileme & $0.311 \mathrm{bc}$ & 0.84 & Kendileme & 0.427 & 1.00 \\
\hline Memecik & $0.335 a b$ & 0.91 & Memecik & $0.518 a$ & 1.00 & Memecik & 0.424 & 1.00 \\
\hline Edincik & $0.233 a b c$ & 0.63 & Gemlik & $0.510 a$ & 1.00 & Çekişte & 0.413 & 1.00 \\
\hline Ayvalık & $0.223 \mathrm{bc}$ & 0.60 & Erkence & $0.467 a b$ & 1.00 & Erkence & 0.411 & 1.00 \\
\hline Tavşan yüreği & $0.219 \mathrm{bc}$ & 0.59 & Tavşan yüreği & $0.412 a b c$ & 1.00 & Gemlik & 0.399 & 0.99 \\
\hline Erkence & $0.213 b c$ & 0.58 & Ayvalık & $0.281 b c$ & 0.76 & Edincik & 0.375 & 0.93 \\
\hline Çekişte & $0.178 \mathrm{c}$ & 0.48 & Edincik & $0.240 \mathrm{c}$ & 0.65 & Tavşan yüreği & 0.337 & 0.83 \\
\hline
\end{tabular}

SBDM: Somak başına düşen meyve miktarı, $R=$ Verimlilik indeks değeri

*Ortalamalar Student's t testine $(p<0,05)$ göre gruplandırılmıştır 
NURENGIN M, ÇETiN Ö, HAKAN M, KAYA H, SEFER F, ULUÇAY N, GÜLOĞLU U, GÜL H, SEZGiN O

Uslu zeytin çeşidinin kendine verimlilik durumu ve bu çeşit için kullanılan tozlayıcıların etkinlik durumlarına ilişkin hesaplanan verimlilik indeks değerleri (R) Çizelge 2'de görülmektedir. Buna göre her üç deneme yılında kendilemelerdeki indeks değerleri birinci yıl 0.36, ikinci yıl 0.84 ve son yıl 1.00 olarak belirlenmiştir. Bu üç değer dikkate alındığında Uslu çeşidinin kendine verimli olduğu söylenebilir. Ancak, Bradley ve ark., (1961); Griggs ve ark., (1975); Androulakis ve Loupassaki, (1990); Bartolini ve Guerriero, (1995); Lavee ve ark., (2002), Mete ve ark., (2012) kendine verimliliğin ve tozlayıcı çeşitlerin etkisinin yıllara bağlı olarak değişebileceğini vurgulamışlardır. Nitekim bu çalışmada da benzer sonuçlara ulaşılmıştır. Çeşidin kendine verimlilik indeks değeri yıllar arasında değişkenlik göstermiştir. Uslu çeşidinde daha önce Mete (2009) tarafından yapılan bir başka çalışmada da çeşidin denemenin ilk yılı kendine verimli, ertesi yıl ise kısmen kendine verimli olduğu ifade edilmiştir. Araştırıcı çeşidin kısmen kendine verimli olabileceğini ifade etmiş ve Gemlik, Memecik çeşitlerini tozlayıcı olarak önermiştir. Ayrıca, Uslu çeşidinin kendine verimlilik ve tozlanma isteğine ilişkin yeni çalışmaların yapılması gerekliliği de ifade edilmiştir. Bu Çizelge 3. Nizip Yağlık çeşidine ait meyve tutum ve verimlilik

\begin{tabular}{|c|c|c|c|c|c|c|c|c|}
\hline \multicolumn{3}{|l|}{ 1. Yll } & \multicolumn{3}{|l|}{ 2. YII } & \multicolumn{3}{|l|}{ 3. YII } \\
\hline Uygulama & SBDM* & $\mathbf{R}$ & Uygulama & SBDM* & $\mathbf{R}$ & Uygulama & SBDM* & $\mathbf{R}$ \\
\hline Serbest tozlanma & $0.432 \mathrm{a}$ & 1.00 & Serbest tozlanma & $0.373 a$ & 1.00 & Serbest tozlanma & $0.375 a$ & 1.00 \\
\hline Kendileme & $0.103 \mathrm{~cd}$ & 0.24 & Kendileme & $0.172 b$ & 0.46 & Kendileme & $0.084 \mathrm{c}$ & 0.22 \\
\hline Memecik & $0.264 \mathrm{~b}$ & 0.61 & Memecik & $0.424 a$ & 1.00 & Ayvalık & $0.386 a$ & 1.00 \\
\hline Kilis yağlık & $0.193 \mathrm{bc}$ & 0.45 & Gemlik & $0.100 \mathrm{~b}$ & 0.27 & Gemlik & $0.361 \mathrm{ab}$ & 0.96 \\
\hline Gemlik & $0.172 b c$ & 0.40 & Ayvalık & $0.086 \mathrm{~b}$ & 0.23 & Kilis yağlık & $0.360 \mathrm{ab}$ & 0.96 \\
\hline Yuvarlak hal. & $0.156 \mathrm{bcd}$ & 0.36 & Saurani & $0.087 \mathrm{~b}$ & 0.21 & Halhalı çelebi & $0.306 \mathrm{ab}$ & 0.82 \\
\hline Eğri burun (N) & $0.155 \mathrm{bcd}$ & 0.36 & Halhalı çelebi & $0.045 b$ & 0.12 & Memecik & $0.302 a b$ & 0.81 \\
\hline Ayvalık & $0.147 \mathrm{bcd}$ & 0.34 & & & & Saurani & $0.172 \mathrm{bc}$ & 0.46 \\
\hline Yağlık çelebi & $0.142 \mathrm{~cd}$ & 0.33 & & & & & & \\
\hline Saurani & $0.045 d$ & 0.10 & & & & & & \\
\hline
\end{tabular}

SBDM: Somak başına düşen meyve miktarı, $R=$ Verimlilik indeks değeri

*Ortalamalar Student's t testine $(p<0,05)$ göre gruplandırılmıştır

İkinci yıl (2013) en yüksek meyve tutum miktarı Memecik (0.424) çeşidiyle tozlanan uygulamada belirlenmiştir. Ancak meyve tutum miktarı 0.373 olan serbest tozlanma ile istatistiksel anlamda bir fark ortaya çıkmamıştır. Gemlik, Ayvalık, Saurani, Halhalı çelebi ve kendileme uygulamaları ise meyve tutum miktarı bakımından farklıklar göstermekle birlikte tamamı aynı grupta yer almıştır.

Üçüncü yıl en yüksek meyve tutum miktarı, istatistiksel olarak aralarında bir fark bulunmayan Ayvalık (0.386) ve serbest tozlanmada (0.375) belirlenmiştir. Diğer tozlayıcı çeşitler olan Gemlik (0.361), Kilis yağlık (0.360), Halhalı çelebi (0.306) ve Memecik (0.302) çeşitleri ise en iyi ikinci grupta yer almışlardır. Aynı yıl en düşük meyve tutumu kendileme (0.084) uygulamasında saptanmıştır.

çalışmadan elde edilen bulgularda yukarda bahsedilen sonuçlarla kısmen benzerlik göstermektedir. Özellikle Memecik ve Gemlik çeşitleri iki yıl üst üste serbest tozlanmadan bile fazla meyve tutumu sağlayarak bir önceki çalışmada önerilen tozlayıcı çeşitlerle paralellik göstermişlerdir. Memecik çeşidi ilk yıl 0.91, ikinci yıl 1.00 ve son yıl 1.00'lık verimlilik indeks değeriyle oldukça uyumlu bir tozlayıcı olarak görülmüştür. Yine Gemlik ve Erkence çeşitlerinin verimlilik indeks değerleri son iki yıl oldukça yüksek bulunmuştur. Bu iki çeşidin de etkili tozlayıcılar olacağı düşünülmektedir.

Nizip Yağlık: Güneydoğu Anadolu Bölgesi'nin önemli bir çeşidi olan Nizip yağlık çeşidinde 2012, 2013 ve 2014 yıllarında gerçekleştirilen serbest tozlanma, kendilenme ve yabancı tozlama uygulamalara ilişkin bulgular Çizelge 3'de bildirilmiştir. Çizelgede görüleceği gibi çalışmanın ilk yılında en yüksek somak başına düşen meyve miktarı 0.432 ile serbest tozlanmada saptanmıştır. Bu uygulamayı; 0.264 ile Memecik, 0.193 ile Kilis yağlık, 0.172 ile Gemlik, 0.156 ile Yuvarlak Halhalı, 0.155 ile Eğri burun (Nizip), 0.147 ile Ayvalık, 0.142 ile Yağlık çelebi, 0.103 ile kendileme ve 0.045

ile Saurani izlemiştir.

indeks (R) değerleri 
çeşitler iyi tozlayıcı sınıfında yer almışlardır. Üç yıllık değerlendirmeler sonucunda Memecik ve Kilis yağlık çeşitlerinin Nizip yağlık çeşidi için uygun tozlayıcılar olabileceği düşünülmektedir.

Saurani: Saurani çeşidinde yapılan uygulamalara ilişkin veriler Çizelge 4'de verilmiştir. Çizelgede görüleceği gibi çalışmanın birinci yılında somak başına düşen meyve miktarı Çizelge 4. Saurani çeşidine ait meyve tutum ve verimlilik indeks (R) değerleri

\begin{tabular}{lllllllll}
\hline 1. yıl & & \multicolumn{3}{c}{ 2. yıl } & & & 3. yıl & \\
Uygulama & SBDM* & $\mathbf{R}$ & Uygulama & SBDM & $\mathbf{R}$ & Uygulama & SBDM & $\mathbf{R}$ \\
\hline Serbest tozlanma & $0.500 \mathrm{ab}$ & 1.00 & Serbest tozlanma & 0.418 & 1.00 & Serbest tozlanma & 0.469 & 1.00 \\
Kendileme & $0.301 \mathrm{c}$ & 0.60 & Kendileme & 0.221 & 0.53 & Kendileme & 0.381 & 0.81 \\
Gemlik & $0.666 \mathrm{a}$ & 1.00 & Halhalı çelebi & 0.473 & 1.00 & Gemlik & 0.467 & 0.99 \\
Egri burun (N) & $0.417 \mathrm{bc}$ & 0.83 & Gemlik & 0.353 & 0.84 & Halhalı çelebi & 0.460 & 0.98 \\
Memecik & $0.374 \mathrm{bc}$ & 0.75 & Memecik & 0.346 & 0.83 & Ayvalık & 0.435 & 0.93 \\
Sarı ulak & $0.349 \mathrm{bc}$ & 0.70 & Eğri burun (N) & 0.315 & 0.75 & Memecik & 0.426 & 0.91 \\
Nizip yağlık & $0.334 \mathrm{bc}$ & 0.67 & Nizip yağlık & 0.304 & 0.73 & Nizip yağlık & 0.400 & 0.85 \\
Yağlık çelebi & $0.323 \mathrm{bc}$ & 0.65 & Ayvalık & 0.187 & 0.45 & Eğri burun (N) & 0.334 & 0.71 \\
\hline
\end{tabular}

SBDM: Somak başına düşen meyve miktarı, $\mathrm{R}=$ Verimlilik indeks değeri

*Ortalamalar Student's t testine $(p<0,05)$ göre gruplandırılmıştır

Çalışmanın ikinci yılında (2013) uygulamalar arasında istatistiksel anlamada farklılık bulunmamıştır. Bu yıl içerisinde en yüksek meyve tutum miktarları sırasıyla 0.473 ile Halhalı çelebi, 0.418 ile serbest tozlanma, 0.353 ile Gemlik, 0.346 ile Memecik, 0.315 ile Eğri burun (Nizip), 0.304 ile Nizip Yağlık, 0.221 ile kendileme ve 0.187 ile Ayvalık uygulamasında belirlenmiştir. Çalışmanın üçüncü yılında da (2014) uygulamalar arasında istatistiksel anlamada farklılık bulunmamıştır. Uygulamaların meyve tutum miktarları 0.469 (Serbest) ile 0.334 (Eğri burun-Nizip) arasında değişim göstermiştir. Diğer uygulamalar bu iki değer arasında yer almıştır.

Saurani zeytin çeşidinin kendine verimlilik durumu ve bu çeşit için kullanılan tozlayıcıların etkinlik durumlarına ilişkin hesaplanan verimlilik indeks değerleri (R) Çizelge 4'de görülmektedir. Buna göre kendilemelerdeki indeks değerleri birinci yıl 0.60 , ikinci yıl 0.53 ve son yıl 0.81 olarak belirlenmiştir. Bu üç değer dikkate alındığında Saurani çeşidinin kendine verimli olduğu söylenebilir. Çalışma süresince kullanılan tozlayıcı çeşitlerin meyve tutumuna etkileri yıllar arasında bazı farklılıklar göstermiştir. Ancak proje süresince kullanılan bütün tozlayıcılar genelde iyi bir performans göstermiştir. Çizelge 4 'de görüleceği gibi ilk yıl bütün tozlayıcılar kendilemeden daha iyi sonuç vermişlerdir. Sadece ikinci yıl Ayvalık, üçüncü yıl ise Eğri burun (Nizip) çeşitleri kendileme uygulamasının altında kalmış olup diğer çeşitlerin tamamı iyi tozlayıcılar sınıfında yer almıştır.

\section{SONUÇ}

Çalışmadan elde edilen veriler değerlendirildiğinde; Saurani ve Uslu zeytin çeşitlerinin kendine verimli, Nizip Yağlık en yüksek Gemlik (0.666) çeşidiyle tozlanan kombinasyonda saptanmıştır. Bu çeşidi 0.500 ile serbest tozlanma izlemiştir. Diğer uygulamalara ait meyve tutum miktarı ise sırasıyla, Eğri burun (Nizip) 0.417, Memecik 0.374, Sarı ulak 0.349, Nizip Yağlık 0.334, Yağlık çelebi 0.323 ve kendileme 0.301 şekilde olmuştur.

çeşidinin ise kısmen kendine verimli olduğu düşünülmektedir. Ancak daha önceki birçok araştırmada belirtildiği gibi zeytin çeşitlerinde kendine verimliliğin ve tozlayıcıların etkinliğinin yıllar arasında değişiklikler gösterebileceği ortaya konmuştur. Bununla birlikte, meyve tutum oranını arttırması bakımından yabancı tozlanmanın kendileme uygulamasına göre çoğu zaman daha etkili olduğu saptanmıştır. Bu nedenle kendine verimli olduğu düşünülen çeşitlerde dahi yabancı tozlanmanın gerekliliği görülmüştür. Bu doğrultuda Uslu çeşidi için Gemlik, Memecik ve Erkence çeşitlerinin; Saurani çeşidi için Halhalı çelebi, Gemlik, Memecik ve Nizip Yağlık çeşitlerinin ve Nizip Yağlık çeşidi için Memecik ve Kilis yağlık çeşitlerinin uygun tozlayıcılar olarak kullanılabileceği düşünülmektedir. Bu bulgular doğrultusunda mevcut ya da yeni tesis edilen zeytin bahçeleri için çalışmada belirtilen tozlayıcı çeşitlerin kullanılması verimliliğin artmasını sağlayacaktır.

\section{KAYNAKLAR}

Androulakis II, Loupassaki MH (1990) Studies on SelfFertility of Some Olive Cultivars in the Area of Crete. Acta Horticulturae 286: 159-162.

Bartolini S, Guerriero R (1995) Self-compatibility in Several Clones of oil Olive cv. Leccino. Hort. Sci., 9: 71-74.

Bradley D, Griggs WH, Hartmann HT (1961) Studies on Self and Cros Pollination of Olives under Varying Temparature Conditions. California Agriculture 15:45.

Çavuşoğlu A (1970) Ege Bölgesinin Önemli zeytin çeşitlerinin Döllenme Biyolojisi Üzerine Araştırmalar. E.Ü: Ziraat Fakültesi, Uzmanlık Tezi. 
NURENGIN M, ÇETiN Ö, HAKAN M, KAYA H, SEFER F, ULUÇAY N, GÜLOĞLU U, GÜL H, SEZGiN

Farinelli D, Tombesi A, Hassani D (2008) Self-Sterility and Cross-Pollination Responses of Nine Olive Cultivars in Central Italy. Acta Horticulturae, 791: 127-136.

Ferrara E, Papa G, Lamparelli F (2002) Evaluation of the Olive Germplasm in the Apulia Region: Biological and Technological Characteristics. Acta Horticulturae, 586: 159-162.

Griggs WH, Hartmann HT, Bradley MV, Iwakiri BT, Whisler JE (1975) Olive Pollination in California. Bulletin 869. University of California, Davies, CA.

Kaya H, Tekintaş FE (2006) Aydın İlinde Yetiştirilen Yamalak Sarısı Mahalli Zeytin Çeşidinin Fenotipik Özellikleinin Tanımlanması. ADÜ Ziraat Fakültesi Dergisi. 3(2): 6976.

Lavee S, Taryan, J, Levin J, Haksal A (2002) The Significance of Cross-Pollination for Various Olive Cultivars under Irrigated Intensive Growing Conditions. Olivae, 91: 2536.

Lombardo N, Alessandrino M, Godino G, Madeo A (2006) Comparative Observations Regardding the Floral Biology of 150 Italian Olive (Olea europae L.) cultivars. Adv. Hort. Sci. 20: 247-255.

Mete N (2009) Bazı Zeytin Çeşitlerinin Döllenme Biyolojisi Üzerinde Araştırmalar. Ege Üniversitesi Fen Bilimleri Enstitüsü. Yüksek Lisans Tezi.

Mete N, Mısırlı A, Çetin Ö (2012) Determining the Biology of Fertilization and Pollinators in Some Olive Cultivars. Proceedings of the 4th International Conference on "Olive Culture and Biotechnology of Olive Tree Products". P: 69-74.

Mete N, Şahin M, Çetin Ö (2015) Zeytinde Döllenme Biyolojisi. Zeytin Bilimi, 1309-5889. Cilt 5. Sayı 1. S:27.
Mete N, Şahin M, Çetin Ö (2016) Determination of SelfFertility of the 'Hayat' Olive Cultivar Obtained by Hybridization Breeding. Journal of Tekirdag Agricultural Faculty, 13(3): 60-64.

Mete N, Çetin Ö (2017a) Kuzey Kıbrıs Türk Cumhuriyeti'nde Zeytin Gen Kaynaklarının Araştırılması. Ege Üniversitesi. Ziraat Fak. Dergisi. 54 (4):453-457 ISSN $1018-8851$

Mete N, Çetin Ö (2017b) Kilis Yağlık Zeytin Çeşidinde Döllenme Sorununun Araştırılması. Harran Tarım ve Gıda Bilimleri Dergisi. 21(4):376-384.

Moutier N (2002) Self-Fertility and Inter-Compatibilities of Sixteen Olive Varieties. Acta Horticulturae, 586: 209212.

Sütçü AR (1980) Gemlik Zeytininin Döllenme Biyolojisi Üzerine Araştırmalar. E.Ü. Ziraat Fakültesi Uzmanlık Tezi.

Unver T, Wu Z, Sterck L, Turktas M, Lohaus R, Li Z, Yang M, He L, Deng T, Escalante F.J, Llorens C, J Roig F, Parmaksiz I, Dundar E, Xie F, Zhang B, Ipek A, Uranbey $S$, Erayman $M$, Ilhan E, Badad O, Ghazal H, Lightfoot D.A, Kasarla P, Colantonio V, Tombuloglu H, Hernandez P, Mete N, Cetin O, Van Montagu M, Yang H, Gao Q, Dorado G, Van de Peer Y (2017) Genome of Wild Olive and the Evolution of Oil Biosynthesis. Proc. Natl. Acad. Sci. USA 2017, 114, E9413-E9422.

Vulletin Selak G, Perica S, Poljak M, Goreta S, Radunić M, Hartl Musinov D (2006) Compatibility relationships within and between olive (Olea europaea L.) cultivars. 4. Slovenian Symposium on Plant Biology with International Participation . Slovenian Society for Plant Physiology 
